\title{
A política de formação continuada do pacto nacional pela alfabetização na idade certa e a aprendizagem dos alfabetizadores cursistas
}

\author{
The policy of continuing education of the national pact for literacy at the right \\ age and the learning of literacy teachers \\ La política de formación continua del pacto nacional por la alfabetización en la \\ edad correcta y el aprendizaje de los alfabetizadores cursistas
}

FRANCISCA EDILMA BRAGA SOARES AURELIANO Orcid Id: https://orcid.org/0000-0002-6891-8868 Universidade do Estado do Rio Grande do Norte LUIZ CARLOS DA COSTA SILVA JÚNIOR Orcid Id: https://orcid.org/0000-0001-5158-0832 Universidade do Estado do Rio Grande do Norte

\begin{abstract}
Resumo: Este trabalho objetiva analisar as aprendizagens construídas no contexto do PNAIC por professoras que lecionam no ciclo de alfabetização em uma escola pública do município de Patu/RN. A pesquisa foi realizada no Grupo de Pesquisa: Formação, Currículo e Ensino da Universidade do Estado do Rio Grande do Norte entre 2017 e 2018 . A análise teórica, documental e empírica seguiu os princípios do método histórico dialético. Os dados foram analisados pelo procedimento dos núcleos de significação que Aguiar e Ozella (2013, p. 310) orientam. Constatou-se que as docentes se apropriaram de alguns princípios que constituem os conceitos orientados pelo PNAIC, mas outros se encontram em processo de internalização.
\end{abstract}

Palavras-chave: Política de Formação. Formação continuada. Aprendizagem docente.

\begin{abstract}
This paper aims to analyze the learning process in the context of PNAIC by teachers who teach in the literacy cycle in a public school in Patu/RN. The research was held by the research group Curriculum and Teaching of the Federal University of Rio Grande do Norte, between 2017 and 2018. The theoretical, documental, and empirical analysis followed the principles of the historical dialectical method. The data was analyzed through the meaning of the nucleus procedures that Aguiar and Ozella (2013, p. 310) guided. It was noticed that the teachers appropriated some principles that constitute the concepts guided by PNAIC, however, others are still in an internalization process.
\end{abstract}

Keywords: Teacher Training Policies. Continuing Education. Teacher learning. 
Resumen: Este trabajo tiene por objetivo analizar los aprendizajes construidos en el contexto del PNAIC porprofesores que enseñan en el ciclo de alfabetización en una escuela pública de del municipio de Patu/RN. Se realizó la investigación en el Grupo de Investigación: Formación, Currículo y Enseñanza de la Universidad del Estado de Río Grande del Norte entre 2017 y 2018. El análisis teórico, documental y empirico está bajo los principios del método histórico dialéctico. Los datos se analizaron utilizando el procedimiento de núcleos de significado que Agniar y Ozella $(2013$, p. 310) sugieren. Se comprobó que las maestras se apropiaron de algunos principios que componen los conceptos orientados por el PNAIC, pero otros tantos se encuentran en proceso de internalización.

Palabras clave: Politica de formación. Formación continua. Aprendizaje docente.

\section{INTRODUÇÃO}

A política de formação continuada vem sendo alvo de discussões acadêmicas e políticas nas últimas décadas. As mudanças no papel do Estado implicaram em uma série de reformas no âmbito educacional, que vem sendo implantadas na América Latina desde os anos 1990, uma vez que a educação passou a ser considerada um mecanismo de desenvolvimento econômico das nações. Associados às grandes potências econômicas, os organismos internacionais, considerados soberanos, supervisionam a implementação das políticas, com a certificação daqueles governos que atendem os indicadores de qualidade estabelecidos. Garantem, também, a concessão de empréstimos e financiamentos para os governos dos Estados em desenvolvimento que não dispunha de fundos para cumprir as políticas orientadas e desejam melhorar seus indicadores sociais e econômicos.

No Brasil, a formação de professores, como um dos eixos das políticas educacionais, ganha destaque, diante da compreensão de que o alcance dos indicadores preestabelecidos pelas agências credoras depende da melhoria da qualificação e atuação desses profissionais. A partir de então, vêm crescendo acentuadamente os programas voltados para a formação acadêmica do professor e especializações, sendo um mecanismo para uma ressignificação da profissão.

Assim, passa a ser importante que os conhecimentos dos docentes sejam amplos e especializados não somente na linguagem, mas em outras áreas nas quais esteja sempre consagrando a interdisciplinaridade, diversidade, entre outras, colocandose como parte desse contexto, o ciclo de alfabetização. O Pacto Nacional pela Alfabetização na Idade Certa (PNAIC) equivale a um conjunto de ações que tem como eixo principal a formação continuada. Sua proposta busca envolver os professores alfabetizadores e demais profissionais envolvidos com o processo de aprendizagem da leitura e escrita. 
O PNAIC foi instituído como política educacional, através da Portaria $\mathrm{n}^{\circ}$ 867, de 4 de julho de 2012 (BRASIL, 2012b), para atender inicialmente a diretriz II do Plano de Metas Compromisso Todos Pela Educação, implementado pelo Decreto $n^{\circ} 6.094$ de 24 de abril de 2007 (BRASIL, 2007), que estabelece que os sistemas de ensino deve cumprir com a responsabilidade de alfabetizar todas as crianças, no máximo, até os oito anos de idade. Posteriormente, essa diretriz aparece no Plano Nacional de Educação, Lei no 10.172 de 09 de janeiro de 2001 (BRASIL, 2001) que delimita o prazo até o final do $3^{\circ}$ (terceiro) ano do ensino fundamental para que a alfabetização aconteça. No segundo PNE, Lei n ${ }^{\circ} 13.005$ de 25 de junho de 2014, esse compromisso é reafirmado na Meta 5: "alfabetizar todas as crianças, no máximo, até o final do terceiro ano do ensino fundamental." (BRASIL, 2014, p. 58).

Diante desse contexto, buscamos contribuir com os estudos sobre esse programa formativo, abordando neste texto um recorte dos estudos vinculados ao grupo de pesquisa Formação, Currículo e Ensino - FORMACE - da Universidade do Estado do Rio Grande do Norte, sobre as "Aproximações e distanciamentos da formação continuada do PNAIC do trabalho pedagógico do professor alfabetizador" desenvolvido entre 2017 e 2019. Neste artigo, objetivamos analisar as aprendizagens construídas pelos professores sobre os conceitos de alfabetização e letramento que foram abordados durante a formação continuada do PNAIC.

Para tanto, adotamos a abordagem histórica e dialética da pesquisa que compreende a historicidade e a processualidade do ser e, ao criticar os determinismos filosóficos da teoria do conhecimento que se constituem em meio às contradições (LUKÁCS, 2010). A coleta de dados ocorreu através da realização de entrevistas semiestruturadas, feitas com duas professoras que atuam no $1^{\circ} \mathrm{e}$ no $2^{\circ}$ ano do Ensino Fundamental da Escola Municipal Raimundo Nonato. Para resguardá-las em suas identidades, são nomeadas respectivamente no texto por Safira e Esmeralda.

O processo de análise teve como basilar os princípios dos núcleos de significação, orientados por Aguiar e Ozella (2013, p. 310), “[...] entendidos como um movimento superior de abstração, o qual, por meio da articulação dialética das partes - movimento subordinado à teoria -, avança em direção ao concreto pensado, às zonas do sentido". Os dados organizados nos núcleos foram analisados considerando os cadernos de orientação do PNAIC e o referencial teórico basilar deste estudo. Tendo implantado tais princípios na pesquisa, destacamos, neste recorte, os seguintes núcleos de significação que representam as aprendizagens construídas pelos docentes: conceito de alfabetização e conceito de letramento. 
Incialmente, apresentamos o referencial teórico que trata da política de formação continuada e a estrutura do PNAIC; a aprendizagem docente na formação continuada e alfabetização na perspectiva do letramento. Dando sequência, apresentamos a análise dos dados, e por último, as considerações finais com a síntese dos resultados.

\section{POLÍTICA DE FORMAÇÃO CONTINUADA E O PROGRAMA PNAIC}

No cenário de mudanças econômicas, políticas e tecnológicas, a educação vem sendo considerada como mecanismo que proporciona o desenvolvimento das nações, e toma novos delineamentos, passando a se ordenar mediante a definição de princípios e normas na busca de atingir índices satisfatórios nos indicadores econômicos e sociais. Uma vez que essas medidas foram financiadas no âmbito educacional sob forma de políticas públicas, consequentemente, maiores foram as forças regulatórias, de monitoramento e controle social para garantir o desejável padrão de qualidade nos setores aos quais se destinaram recursos.

Cabe ressaltar que o princípio adotado e que fundamenta essas transformações tem por basilar a visão neoliberal que compreende a ação humana como principal fonte de produtividade. Em outras palavras, essa perspectiva “[...] traz implicações em relação às práticas educativas que consolidam a ideologia dominante para o desenvolvimento econômico e interfere na política de formação dos profissionais da educação". (CABRAL NETO, MELO SILVA, SILVA, 2016, p. 35).

É possível ser observado com frequência na constituição das políticas educacionais brasileiras o caráter compensatório que é assumido numa dimensão assistencial. No Brasil, após a realização de avaliações de larga escala, as estatísticas denotaram índices negativos com relação à situação da alfabetização de crianças, jovens e adultos, apontando o aumento na distorção idade-série no ensino fundamental resultante das elevadas taxas de reprovação durante a educação básica, o que impossibilitou o avanço na progressão dos estudos por parte dos alunos.

Diante desse contexto, figura-se a necessidade de reverter os elevados índices de analfabetismo em todo o território nacional que, certamente, expressavam um diagnóstico negativo que empobrece a representatividade do Estado perante os países em nível de desenvolvimento acelerado. Daí emergem novas preocupações com a melhoria da alfabetização, tomando como eixo 
estratégico a formação continuada de professores alfabetizadores, como política compensatória que investe na ideia de que docentes mais capacitados têm mais condições de promover a alfabetização dos seus educandos.

Para tanto, ocorre sucessivamente o surgimento de vários programas, dentre eles: Programa Parâmetros Curriculares em Ação - PCNs em Ação (1998), Programa de Formação de Professores Alfabetizadores - PROFA (2001), Programa de Apoio a Leitura e Escrita - PRALER (2004), Programa de Formação Continuada de Professores das Séries Iniciais do Ensino Fundamental - Próletramento (2006) (AURELIANO, 2012), e Pacto Nacional pela Alfabetização na Idade Certa - PNAIC (2012), esse último um dos mais recentes que esteve em evidência até 2018.

Passemos, então, a analisar como se configura a política de formação continuada do PNAIC que é definido, conforme o caderno de apresentação, como um compromisso formal assumido entre Governo Federal, Distrito Federal, Estados, Municípios e sociedade visando a garantia da plena alfabetização das crianças até os oito anos de idade, ao final do $3^{\circ}$ ano do Ensino Fundamental (BRASIL, 2015a). O programa passou por várias reconfigurações, desde a implementação até seu encerramento em 2018. Em 2013, o foco dos estudos da formação realizada foi em alfabetização na perspectiva do letramento; em 2014, as discussões seguiram em torno da alfabetização matemática; e, em 2015, o estudo foi sobre a interdisciplinaridade.

Em 2016 houve um retorno das discussões sobre alfabetização e letramento e em 2017, com a Portaria no 826, de 7 de julho de 2017, foram incluídos os professores de Educação Infantil e os Oficineiros do Programa Mais Educação no processo de formação continuada. A inclusão da Educação Infantil no Programa apontava para a perspectiva de que o Estado apresentava intenções de diminuir o tempo destinado para alfabetização, incentivando, pelo PNAIC, que já poderia ser iniciada nesta etapa da Educação Básica, o que veio a se efetivar no Decreto n ${ }^{\circ}$ 9.765, de 11 de abril de 2019, que institui a Política Nacional de Alfabetização. Na primeira diretriz deste documento fica estabelecido que a alfabetização deve ocorrer no primeiro ano do ensino fundamental e, na segunda, que os sistemas de ensino devem incentivar as práticas de ensino para o desenvolvimento da linguagem oral e da literacia na educação infantil (BRASIL, 2019).

No âmbito do programa, a formação é ofertada a partir da articulação envolvendo as seguintes entidades: universidades públicas, institutos federais, centros de formação de docentes regularmente instituídos e escolas alfabetizadoras e de educação infantil. O material do programa é composto por: um caderno de apresentação, um caderno para gestores e equipe pedagógica e 
uma coleção de cadernos que abordam teoricamente os temas relacionados ao processo de alfabetização de criança e o que é necessário à formação do professor alfabetizador, bem como apresentam relatos de experiências exitosas a partir do PNAIC e sugestões de atividades. Cada caderno corresponde a uma unidade, que era trabalhada ao longo de uma carga horária de 08 (oito) horas (BRASIL, 2015a).

Ainda no que se refere ao modo como o processo formativo era procedido, mantém-se o caráter verticalizado durante a operacionalização, descrito no caderno de apresentação assim:

O professor formador, profissional selecionado por universidades públicas brasileiras, realiza a formação dos orientadores de estudo. O orientador de estudos, por sua vez, selecionado pelos municípios, a partir de critérios estabelecidos pelo MEC, organiza, com base nos mesmos princípios formativos, a formação dos professores alfabetizadores, atuantes nos três primeiros anos, em escolas públicas de diversas regiões do País. (BRASIL, 2015a, p. 28).

Esperava-se, com a formação por meio do subsídio dos cadernos, promover o aperfeiçoamento do professor em serviço, que deve assumir uma postura interdisciplinar na abordagem do processo educativo, passando a investir também na perspectiva do alfabetizar letrando. No caderno intitulado "Currículo na Alfabetização: concepções e princípios” (BRASIL, 2012a), em consonância com os direitos gerais de língua portuguesa, são apresentadas as competências básicas que os alunos devem desenvolver ao longo do ciclo de alfabetização em relação à apropriação do Sistema de Escrita Alfabética - SEA, as quais estão listadas a seguir:

- Escrever o próprio nome.

- Reconhecer e nomear as letras do alfabeto.

- Diferenciar letras de números e outros símbolos.

- Conhecer a ordem alfabética e seus usos em diferentes gêneros.

- Reconhecer diferentes tipos de letras em textos de diferentes gêneros e suportes textuais.

- Usar diferentes tipos de letras em situações de escrita de palavras e textos.

- Compreender que palavras diferentes compartilham certas letras.

- Perceber que palavras diferentes variam quanto ao número, repertório e ordem de letras. 
- Segmentar oralmente as sílabas de palavras e comparar as palavras quanto ao tamanho.

- Identificar semelhanças sonoras em sílabas e em rimas.

- Reconhecer que as sílabas variam quanto às suas composições.

- Perceber que as vogais estão presentes em todas as sílabas.

- Ler, ajustando a pauta sonora ao escrito.

- Dominar as correspondências entre letras ou grupos de letras e seu valor sonoro, de modo a ler palavras e textos.

- Dominar as correspondências entre letras ou grupos de letras e seu valor sonoro, de modo a escrever palavras e textos. (BRASIL, 2012a, p. 37).

Todas essas competências, segundo as orientações do PNAIC, são necessárias para a apropriação do Sistema de Escrita Alfabética - SEA, defendidas também por Morais (2004) como princípios desse sistema. É fundamental que o trabalho pedagógico do professor alfabetizador seja mediado pelo planejamento sistemático e racional, com ancoragem nos pressupostos teóricos que deram sustentação à formação. Além disso, o programa orienta a intervenção de encaminhamentos metodológicos que podem ser tomados pelo docente com o propósito de propiciar o avanço dos educandos na aprendizagem. Assim, todas essas orientações expostas aqui precisam ser efetivadas no contexto das práticas de alfabetização para que se concretize a Meta 5 traçada pelo PNE (BRASIL, 2014).

A formação continuada de natureza unicamente instrumental é criticada por Candau (1996) quando se organiza por uma série de conteúdos e metodologias vazias de articulação com suas vivências e experiências ao longo do seu desenvolvimento profissional.

A formação continuada não pode ser concebida como um processo de acumulação (de cursos, palestras, seminários, etc., de conhecimentos ou técnicas), mas sim como um trabalho de reflexibilidade crítica sobre a prática de (re) construção permanente de uma identidade pessoal e profissional, em interação mútua. (CANDAU, 1996, p. 150).

Levando em conta o que fora exposto nesta seção, é nítido que o Estado demonstra certa preocupação em promover a alfabetização dos seus cidadãos, principalmente, ao se considerar as investiduras feitas nessa área. Sem dúvida, a constituição de políticas e a disposição de recursos tornam-se condições essenciais para uma educação de qualidade. No entanto, no que se refere ao PNAIC, apesar de explicitar a mobilização de muitos atores no âmbito dos encontros de formação, é preciso atentar para a verticalização em que se estruturava o programa, o que põe em dúvida em que circunstâncias o curso de formação continuada dialogou com as necessidades dos docentes em seu trabalho educativo. 


\section{APRENDIZAGEM DOCENTE NA FORMAÇÃO CONTINUADA}

A docência na atualidade tem sido impactada pelas mudanças estruturais nas bases da sociedade exclamada como sendo do conhecimento e da informação. Isso intima os professores do ensino básico e superior a se inovarem para formar as futuras gerações de modo coerente com as características do projeto societário em construção. Nessa atmosfera da modernidade, para ocorrer a aprendizagem docente é necessário a continuidade no bojo de sua formação. O professor é um adulto em aprendizagem, e esta consiste em um desafio no cenário acadêmico, visto que as teorizações da psicologia apresentam, tradicionalmente, predominância nos estudos da criança e do adolescente e deixa uma lacuna nos processos de desenvolvimento e aprendizagem específicos do adulto.

Partimos dos estudos da psicologia histórico-cultural, em que Vygotsky (2007) vincula o desenvolvimento das funções psíquicas tipicamente humanas às condições históricas e socioculturais de vida de cada sujeito e à mediação social e simbólica. Nessa perspectiva, destaca-se o papel do outro e da linguagem na relação entre aprendizagem e desenvolvimento na descrição do construto Zona de Desenvolvimento Proximal, segundo o qual o desenvolvimento humano precisa ser compreendido não como algo cristalizado, mas em movimento mediante o papel do meio social. (VYGOTSKY, 2009).

Nesse conceito, todas as funções envolvem, em seu desenvolvimento, níveis de desenvolvimento real, caracterizado por ações e operações que o sujeito já elaborou e já consegue realizar sem intervenção do meio social; e de desenvolvimento proximal ou potencial, caracterizado por ações, operações, cuja realização só se torna possível mediante intervenções de outros da cultura, mas que, gradativamente, nas ações compartilhadas, vai dominando e internalizando seus mecanismos, tornando-os seus. Nesse movimento, as aprendizagens consolidadas impulsionam o desenvolvimento daquela função de um nível proximal (potencial) para um nível real (de consolidação).

Dessa perspectiva, descortina-se o papel determinante da educação e das instituições educativas na história de vida de cada indivíduo - em todas as suas fases. O que é ensinado de forma coletiva ao professor nos momentos de formação é internalizado de forma individual e singular e nem sempre corresponde às intenções de quem ensina, ou seja, o que é pertinente ou significativo ao sujeito que aprende, às vezes pode ser impróprio ou impertinente àquele que ensina (SMOLKA, 2000). As afirmações da autora apontam que há sempre diferenças e defasagens entre o que circula como discurso valorizado socialmente e legitimado 
em teorias, leis, normas oficiais e programas curriculares e o que é concebido pelos sujeitos, como também entre o que eles se apropriam como discurso e o que, de fato, realizam em suas ações.

Pensando no adulto como sujeito de aprendizagem, a cada momento da vida e situação, esse sujeito dispõe de uma estrutura conceitual formada por uma rede de conceitos interligados (conhecimentos), constituída pelos conteúdos culturais que vai acumulando ao longo da vida por meio da experiência sociocultural e da mediação simbólica. Esse universo cultural-conceitual - suas significações e sentidos - funciona como filtro que tem a função de interpretar os fatos, eventos ou situações do mundo objetivo e serve de base para novas aprendizagens, tanto como abertura, quanto como resistência. Assim, as propostas de formação precisam levar em consideração que a aprendizagem docente envolve a (trans) formação de conceitos e, por isso, é necessário que se proponham estratégias formativas que intervenham no processo de aprendizagem conceitual dos professores de forma desafiadora, pois a formação de conceitos surge sempre no processo de solução de algum problema que se coloca para o pensamento (VYGOTSKY, 2009, p. 237).

Assim, ao se pensar na formação do professor, deve-se considerar como oportunizar situações em que esse profissional revisite/problematize os conceitos, ideias, concepções que já se encontram consolidados sobre o seu trabalho pedagógico, para que possa, por meio do acesso - mediado - a novas informações, ideias, conceitos e modos de ação e da experimentação dos mesmos (em zona de desenvolvimento proximal, portanto, intervenções e ajudas sistemáticas) reconstruir seus saberes prévios e introduzir mudanças em suas atividades novos entendimentos.

Considerando o professor como sujeito que aprende, os pressupostos sobre aprendizagem e desenvolvimento postos por Vygotsky (2007) se aplicam à formação de professores, compreendendo-a como uma atividade que tem como objetivo oportunizar aprendizagem para sujeitos que são responsáveis pelo ensino a outros. Por outro lado, enquanto adulto que trabalha - atividade social na qual e pela qual se definem funções psicológicas individuais - o professor é portador de um conjunto de conceitos, procedimentos, sentimentos, atitudes e valores decorrentes de toda a sua vivência cultural sobre as formas de se ensinar e aprender.

Ao adentrar em novas oportunidades de formação, é colocado para pensar e agir através das estratégias postas pelo professor/formador e pelos colegas de profissão - que são mediadores de conhecimentos - sobre suas posturas pedagógicas frente aos alunos para que possa reconstruir seus conceitos anteriores sobre o que é ensinar e aprender, para que, para quem, o que e como ensinar e 
aprender. As propostas de formação precisam considerar esses saberes anteriores e buscar entender o que é significativo para o professor, ou seja, o que ele já sabe e o que ampliar em seu universo de significados sobre o seu fazer pedagógico, tendo em vista que, por cada um apresentar construções cognitivas diferentes sobre determinado assunto ou conteúdo mediante a quantidade ou qualidade das interações que lhe foram proporcionadas ao longo da vida e da formação, serão diferentes os níveis de aprendizagem e serão, igualmente diferentes as demandas de intervenção na Zona de Desenvolvimento Proximal.

\section{ALFABETIZAR NA PERSPECTIVA DO LETRAMENTO: FUNDAMENTOS DA FORMAÇÃO CONTINUADA DO PNAIC}

O processo de alfabetização traz imanente complexidades em sua dimensão que estão associadas, de certo modo, às próprias condições de aprendizagem de cada educando no ciclo de alfabetização $\left(1^{\circ}\right.$ ao $3^{\circ}$ ano do Ensino Fundamental). Em contrapartida, sabemos que cada criança responde a esse processo em um ritmo distinto, que é singular e individual.

No centro das tendências teóricas atuais, o foco direcionado sobre como intervir de maneira significativa para a promoção do processo de alfabetização nos reporta para a perspectiva do alfabetizar letrando, com vistas à superação da abordagem tradicional, que compreende a aquisição da aprendizagem da leitura e da escrita como um processo de decodificação e codificação das letras do alfabeto para gradativamente memorizar sentenças de frases e textos curtos oriundos de trabalho isolado. Isso envolvia a "[...] ênfase na repetição e na memorização de letras, sílabas e palavras sem significados”. (ALBUQUERQUE, 2007, p. 13).

Em oposição a essa concepção, a proposta do alfabetizar letrando enaltece a importância de o professor abordar, durante a mediação da aprendizagem dos educandos na alfabetização, os usos e funções sociais da leitura e escrita em seu contexto de circulação. É, então, sob influência de tais proposições que vem se justificar e encontra firmamento a relevância dos gêneros textuais para embasar a realização do trabalho educativo, haja vista a natureza diversificada que dentro de suas características estruturais atende aos propósitos sociocomunicativos no meio social.

Essas premissas põem evidência a forma que se manifesta o letramento na sua indissolúvel relação com a alfabetização, que, conforme definido por Soares (2004, p.14), 
Não são processos independentes, mas interdependentes, e indissociáveis: a alfabetização desenvolve-se no contexto de e por meio de práticas sociais de leitura e de escrita, isto é, através de atividades de letramento, e este, por sua vez, só se pode desenvolver no contexto da e por meio da aprendizagem das relações fonema-grafema, isto é, em dependência da alfabetização". (SOARES, 2004, p.14).

O sentido de complementaridade entre ambos se estabelece devido à condição adquirida pelas práticas de leitura e escrita mobilizadas de maneira acentuada na organização da sociedade, passando a intensificar o contato cada vez mais aproximado dos cidadãos com algum tipo de material escrito. Daí provém a razão de não existir grau zero de letramento, diante também da incapacidade de mensurar o grau máximo de uma pessoa letrada. (MORTATTI, 2004)

Entretanto, apesar das práticas de leitura e escrita virem ocorrendo no cotidiano de forma ainda mais estreita, a busca por propiciar um ensino que leve em conta a variedade de gêneros textuais, por si só, não garante que os alunos se apropriem automaticamente da linguagem escrita convencional, a qual conhecemos por Sistema de Escrita Alfabética (SEA). Albuquerque (2007, p. 20) vem nos explicar que a apropriação desse sistema envolve a análise e reflexão no âmbito da palavra, respeitando alguns critérios no desenvolvimento das atividades no ciclo de alfabetização, são eles:

- uma reflexão sobre suas propriedades: quantidade de letras e sílabas, ordem e posição das letras, etc.

- a comparação entre palavras quanto à quantidade de letras e sílabas e à presença de letras e sílabas iguais;

- a exploração de rimas e aliteração (palavras que possuem o mesmo som em distintas posições (inicial e final, por exemplo)

Assim, percebe-se que para internalizar a aprendizagem das tecnologias ler e escrever é fundamental que o aluno reflita sobre a escrita, percebendo sua relação com a pauta sonora, passando a compreensão real do funcionamento desse sistema notacional organizado por grafemas/fonemas, para que possa ir construindo suas hipóteses de escrita. $\mathrm{Na}$ ocasião, o professor alfabetizador, ao realizar a mediação dessa aprendizagem recorrendo aos gêneros textuais, contribui para que os educandos entendam que cada tipo de texto apresenta uma funcionalidade diferente, bem como concebam a escrita como mecanismo de documentação de informações, linguagens e pensamentos; tudo isso mostra o quão proveitoso pode ser a perspectiva do alfabetizar letrando.

Tal ideário se faz presente na tessitura do PNAIC no âmbito de seus pressupostos de formação, enquanto programa que tem enfatizado as condições materiais e pedagógicas para que a alfabetização das crianças seja conquistada 
no tempo certo, vem apoiar a importância de que o trabalho educativo seja subsidiado pela solidez e intencionalidade ao ser desenvolvido pelos professores cursistas em sala de aula, vindo a propiciar que "[...] as crianças compreendam o funcionamento do sistema de escrita [...]” (BRASIL, 2015b, p. 44).

Recobrando a discussão sobre a alfabetização na perspectiva do letramento, Soares (2006, p. 47, grifos da autora) cita a relação entre alfabetizar e letrar:

[...] alfabetizar e letrar como duas ações distintas, mas não inseparáveis, ao contrário: o ideal seria alfabetizar letrando, ou seja: ensinar a ler e a escrever no contexto das práticas sociais da leitura e da escrita, de modo que o indivíduo se tornasse, ao mesmo tempo, alfabetizado e letrado.

Diante desse pensamento, considera-se alfabetizado o indivíduo que domina as capacidades de ler e escrever; e letrado quando participa de maneira intencional ou não dos usos e funções sociais da leitura e escrita ao serem mobilizadas nas relações em sociedade. Esta afirmação da autora é pertinente ao nos darmos conta do imperativo que a escrita vem exercendo na contemporaneidade, principalmente nas interações sociais, sendo utilizada como forma de comunicação e expressão entre as pessoas, nas propagandas a serviço dos meios de produção e ainda no meio social e cívico como um todo, em que há o predomínio do registro escrito com validade primária. Com efeito, considerando os estudos de Soares (2004), de que a alfabetização e o letramento devem se dar por ações inter-relacionadas, atualmente, passou-se a exigir ainda mais do professor alfabetizador competência, dentre outras habilidades, para atender a essas novas demandas em relação ao perfil do educando que está em processo de aprendizagem.

Essas proposições têm marcado a formação continuada do PNAIC, pois, ao se comprometerem com a qualificação dos professores atuantes no ciclo de alfabetização, os sistemas de ensino buscam garantir às crianças não só o acesso à leitura e à escrita, mas que se tornem usuários competentes na vida social. É indispensável uma prática docente reflexiva para intervir no contexto de ensino e da aprendizagem da leitura e da escrita.

\section{APRENDIZAGENS DOS PROFESSORES NA FORMAÇÃO CONTINUADA DO PNAIC: ANÁLISE DA REALIDADE}

Os cursos de formação continuada são oportunidades de promover aos docentes a reflexão sobre a prática à luz dos conteúdos teóricos, para possibilitar uma reconstrução permanente do fazer pedagógico e com isso possibilitar a 
aprendizagem dos alunos. O PNAIC, enquanto programa formativo, apresentava conteúdos e estratégias metodológicas significativas para alfabetizar na perspectiva do letramento. Sua implementação se deu de forma unificada em todas as escolas brasileiras, sem apresentar uma análise sobre as condições físicas e pedagógicas que marcam as especificidades de cada instituição de ensino, e, principalmente, das salas de aulas, dos alunos e dos professores.

Estruturamos os dados das entrevistas realizadas com as professoras colaboradoras que lecionam na Escola Municipal Raimundo Nonato em núcleos de significação a partir dos sentidos e significados emitidos nas falas das professoras, dos quais recortamos: o conceito de alfabetização e o conceito de letramento. A partir dos conteúdos abordados nos cadernos do Programa e do referencial teórico que fundamentaram a pesquisa, foi possível analisar os conceitos que as docentes Safira e Esmeralda construíram na formação do PNAIC e os que ainda se encontram em fase de elaboração.

Quanto ao conceito de alfabetização as professoras apresentam a seguinte compreensão:

[...] Bom... alfabetização em si acho que é a criança começar esse processo de leitura, de codificação, de ter o domínio das letras. (...) A questão da alfabetização como eu já disse anteriormente não é apenas a codificação de símbolos. Eu saber o que é o "A" eu saber o que é o "B", mais é quando você já tem o processo de você juntar as letrinhas e começar a formar palavra, começar a questão mesmo no processo de ler. (SAFIRA. Entrevista. Patu/RN, 09/03/2018).

[...] Alfabetização para mim é você procurar, primeiramente, não só conhecer o que esse aluno já sabe, mas também desenvolver atividades que facilite o processo de ensino e aprendizagem dessa criança, através não só de ensinar a eles o alfabeto, mas também de eles conhecerem o alfabeto e a função, né, dessas letras, para quê que servem e como contextualizar essa leitura no meio em que ela vive. E eu... assim, alfabetizar é você fazer com que o aluno aprenda, primeiramente, conhecer a letra, depois ele vai conhecer o som de cada letra... tem esse processo de juntar essas letras formando sílabas e depois desenvolver a questão da leitura. (ESMERALDA. Entrevista. Patu/RN, 09/03/2018).

A fala da professora Safira demonstra apropriação do conceito de alfabetização conforme as orientações do programa formativo, que compreende a alfabetização indo além da decodificação das palavras e destaca a importância do conhecimento de alguns princípios que são básicos para apropriação do Sistema de Escrita Alfabética (SEA), como a identificação das letras do alfabeto como o primeiro passo da alfabetização, como destaca os estudos de Albuquerque (2007). Por outro lado, a professora Esmeralda confunde o processo de alfabetização (apropriação individual do SEA) com o ato de alfabetizar (ação docente mediadora no processo de alfabetização). Mas ao destacar o que deve ensinar 
inicialmente, revela o que o aluno deve aprender para que se alfabetize, deixando claro o que o aluno precisa saber para aprender a ler que são: o conhecimento das letras e desenvolver a consciência grafo-fonológica, que são saberes necessários ao processo de alfabetização, conforme orienta o PNAIC (BRASIL, 2015b; MORAIS, 2004).

Nas entrelinhas das falas das professoras, é nítido que Safira e Esmeralda em suas concepções, demonstram que atribuíram sentidos e significado aos pressupostos dos cadernos do PNAIC para conceituar alfabetização, pois elencam de forma indireta que a alfabetização não se resume simplesmente à capacidade de decodificar e codificar letras e sílabas, elas atentam para o uso e funcionalidade das letras nas sílabas e como estas formam as palavras para dar sentido ao texto que será lido. Porém, pouco se adentram sobre a alfabetização como apropriação do SEA, que é notacional, tem suas especificidades e precisam ser aprendidas pelos alunos para que se alfabetizem, como afirma Morais (2004).

Conforme os depoimentos das entrevistadas, percebe-se que os cadernos do programa são tomados como subsídios no que diz respeito ao entendimento sobre o conceito de alfabetização, bem como se refletem nas suas práticas docentes, como expressam os relatos acima. Em consonância a isso, Brasil (2015a, p. 21) notifica que "[...] é preciso que o professor tenha clareza do que ensinar e como ensinar e sobre qual concepção de alfabetização está subjacente à sua prática."

Albuquerque (2007) compreende alfabetização como a aprendizagem das tecnologias ler e escrever. No processo dessas aprendizagens, é fundamental que o aluno reflita sobre a escrita, percebendo sua relação com a pauta sonora, passando a compreensão real do funcionamento desse sistema notacional organizado por grafemas/fonemas, para que possa ir construindo suas hipóteses de escrita. $\mathrm{Na}$ ocasião, o professor alfabetizador, para mediar essa aprendizagem, precisa recorrer aos gêneros textuais, pois isso contribui para que os educandos entendam que cada tipo de texto apresenta uma funcionalidade diferente, bem como deve conceber a escrita como mecanismo de documentação de informações, linguagens e pensamentos; tudo isso mostra o quão proveitoso pode ser a perspectiva do alfabetizar letrando, conhecimentos que estão presentes nos posicionamentos das alfabetizadoras quando tentam conceituar alfabetização.

O professor alfabetizador tem em sua prática o desafio de alfabetizar as crianças, sendo esse o maior estímulo para que busque compreender como a criança aprende e como o professor deve intervir nesse processo, pois, como nos afirma Vygotsky (2009), a elaboração conceitual ocorre quando o sujeito tenta resolver algum problema que desafia seu pensamento. Essa elaboração ocorre nos processos de significação que se dão nas relações que as docentes estabelecem 
nos processos formativos e nas experiências que desenvolvem no contexto de suas práticas. Isso exige replanejamentos contínuos e sistemáticos, contribuindo para um refazer de suas práticas.

Esse refazer se torna possível quando os processos formativos refletem os desafios da escola, discutidos na coletividade, aspecto que nem sempre os programas formativos do governo federal atendem, uma vez que são construídos por especialistas e técnicos que discutem as teorias e tentam associar as práticas vivenciadas pelos docentes. Canário (2000) defende que a aprendizagem profissional deve ocorrer nas instituições em que o trabalho se realiza, no casso dos professores, é preciso considerar a totalidade da escola.

No que se refere ao conceito de letramento, o PNAIC orienta que a ação seja planejada "[...] com foco no que os alunos podem aprender para ampliar seus horizontes culturais e agir na sociedade de modo crítico, pois, ao ensinarmos a ler, ensinamos também os conteúdos tratados nos textos que são lidos." (BRASIL, 2015b, p. 44). Nesses termos está evidente que o programa formativo orienta uma prática alfabetizadora conectada ao termo letramento, pois a escrita tem imperado cada vez mais nas situações públicas e privadas das vivências sociais. Assim, não basta ler e escrever, é preciso que essas práticas estejam a serviço dos indivíduos em suas necessidades.

Espera-se do professor alfabetizador que recebeu a formação do PNAIC contemple o letramento na abordagem do processo de aquisição da leitura e escrita, pois este se manifesta sempre que mobilizamos essas práticas em alguma ocasião dentro do contexto social de seus usos. Buscamos saber como o conceito de letramento se apresenta nas falas das professoras nos trechos a seguir:

[...] o letramento a gente já sabe que é a questão social da leitura. Por que eu leio? Pra que eu leio? Pra que serve a leitura, né? Eu vou ler uma receita de bolo, eu vou saber pra que é que eu tenho que saber o que é aquela receita de bolo, né? Qual é a função social daquela receita de bolo? É isso que antigamente dizia que alfabetizado era todo aquele que lia, mas se você ler e você não compreende o processo de leitura você apenas decodifica símbolos, né? E na criança primeiro ela tem que ter esse processo, de conhecer, de codificar pra depois ela entrar no processo do letramento. (SAFIRA. Entrevista. Patu/RN, 09/03/2018).

[...] o letramento é quando a criança consegue olhar para o que está ao seu redor e fazer a leitura daquilo que ela tá vendo. O letramento é você ler sem saber ler. É como, por exemplo, ele vai passando em frente a um restaurante e vê que tem um garfo e uma faca, então ele já faz aquela ligação, né, daquele símbolo, daquele sinal, com o que ele está vendo. Então, a criança ela pode ser letrada e não alfabetizada. Mas o letramento que eu entendo é isso... é você ter uma leitura do mundo que você vive, uma contextualização do mundo que ele vive. (ESMERALDA. Entrevista. Patu/RN, 09/03/2018). 
Reconhecemos, nos discursos das professoras, que ambas têm um significativo entendimento do conceito de letramento, conforme orienta os materiais do programa, e tentam materializá-lo com exemplos de suas práticas. Mas Safira demonstra separar o processo de alfabetização do processo de letramento quando diz que "[...] criança primeiro ela tem que ter esse processo, de conhecer, de codificar pra depois ela entrar no processo do letramento". Compreendemos que, ao nascer, a criança já se insere nas práticas sociais de utilização da leitura e da escrita. Nesse sentido, como processos diferentes, porém indissociáveis (SOARES, 2006), o letramento precisa fazer parte da vivência do ensino da escrita desde o início da escolarização infantil.

A professora Esmeralda, por sua vez, associa o letramento com a leitura de mundo para contextualizar as práticas de ensino com o contexto social dos alunos. Assim, podemos perceber que ela entrelaça em sua fala o discurso de Freire (1989) de que a leitura do mundo precede a leitura da palavra. Apesar do autor não discutir o termo letramento, os sentidos do seu posicionamento estão relacionados a ele, visto que ecoam nos conhecimentos de que Esmeralda demonstra ter se apropriado em outros momentos formativos, considerando que os estudos de Freire não fundamentaram as orientações da formação continuada do PNAIC.

Esses dados evidenciam que a construção de conceitos pelos docentes ocorre em diversas situações de interações ocorridas nas relações estabelecidas em suas experiências e vivências. Para aprender, os professores se apropriam das características dos objetos do real ou conteúdo e conceitos em discussão que se constituem em significados sociais, mediante os quais, e em sua história, os sujeitos constroem sentidos próprios. Mas, as apropriações das características dos objetos ou conteúdos não acontecem de uma única vez, sendo necessária a permanente mediação de outros portadores da cultura. Esse processo não é, portanto, imediato/direto, nem linear, nem de pura reprodução.

Nesse sentido, as professoras, ao expor suas compreensões e conhecimentos sobre alfabetização e letramento, demonstram conhecimentos construídos em várias oportunidades de formação e/ou em suas vivências pedagógicas com seus pares no contexto da escola. No processo de aprendizagem explicado por Vygotsky (2007), a internalização, enquanto - reconstrução interna de uma operação externa, consiste em apropriação gradual, resultante de reiteradas experimentações dos objetos da cultura, marcada por idas e vindas e transformação de conceitos de que o sujeito já tinha apropriação.

Diante do exposto, é possível perceber a importância do PNAIC no processo de apropriação dos conceitos de alfabetização e letramento por parte das professoras entrevistadas. Por outro lado, ao compreendermos a formação como 
um processo contínuo, percebemos algumas lacunas teóricas na aprendizagem dos princípios e conhecimentos inerentes a esses conceitos, que se encontram na Zona de Desenvolvimento Proximal. Ao mesmo tempo, as docentes também demonstraram propriedade de outros conhecimentos que não foram abordados no programa formativo e que são resultantes de suas experiências ou de outras formações que tiveram acesso ao longo de sua carreira profissional.

O que se observa no PNAIC, de forma geral, é que, como outros programas formativos implementados anteriormente pelo Ministério da Educação, são propostas organizadas sem a consulta pública das necessidades formativas dos docentes. Estes apresentam contextos diversos de trabalho que nem sempre correspondem à realidade universalizada que as formações continuadas oficiais apresentam. Nas políticas formativas que não tem o fazer pedagógico dos docentes como o centro, “[...] eles não se envolvem, não se apropriam dos princípios, não se sente estimulados a alterar sua própria prática, mediante alternativas de ação, ao mesmo tempo em que se recusam a agir como meros executores de propostas externas" (GATTI; BARRETO, p. 201-202, 2009). É preciso que os momentos de formação para professores busquem sempre promover a reflexividade sobre o que estes já sabem diante do que será abordado e sobre o que precisam saber para melhor reconstruírem suas práticas, bem como promovam estudos e ações que estejam de acordo com suas necessidades formativas para que atribuam sentidos e significados ao que são desafiados + a aprender.

\section{CONSIDERAÇÕES FINAIS}

A formação continuada de professores é uma exigência atual, vista como um mecanismo emergente para a melhoria da qualidade de ensino. As políticas de formação docente estão na agenda governamental, sendo o Pacto Nacional de Alfabetização na Idade Certa-PNAIC uma delas, tendo sido implementado entre 2012 e 2013. Seu principal objetivo foi o de possibilitar aos docentes qualificação para melhorar os indicadores de alfabetização infantil, que ainda apresenta dados alarmantes de analfabetismo no cenário nacional.

O PNAIC apresenta um modelo formativo unificado para todo o território brasileiro, que nem sempre atende às necessidades formativas dos docentes, tão diversas diante das condições existenciais em que realizam seu trabalho pedagógico. Mas foi uma oportunidade de reunir de 2013 a 2018 uma grande quantidade de professores que lecionam no sistema público de ensino no ciclo de alfabetização. Neste estudo, atendemos ao objetivo de analisar as aprendizagens construídas pelas professoras que lecionam no $1^{\circ}$ e $2^{\circ}$ ano do Ensino Fundamental sobre os conceitos de alfabetização e de letramento, 
abordados durante a formação continuada do PNAIC. A partir da metodologia histórica e dialética e do procedimento da análise de núcleos de significação dos conteúdos resultantes das respostas das professoras entrevistadas, constatamos que elas se apropriaram de alguns princípios que constituem esses conceitos, e estes se encontram no Nível Desenvolvimento Real de suas estruturas cognitivas, mas outros ainda se encontram na Zona de Desenvolvimento Proximal, ou seja, em fase de elaboração.

Por isso, as professoras necessitam sempre de oportunidade de formação continuada, entendida como momentos em que ocorrerão interações e mediações para que possam avançar na elaboração dos conceitos ainda em fase de elaboração. As professoras destacam alguns princípios básicos para apropriação do Sistema de Escrita Alfabético (SEA), como a aprendizagem das letras do alfabeto e a correspondência grafo-fônica, mas pouco se adentram nas especificidades desse sistema para definir alfabetização, chegando a confundi-los como a prática alfabetizadora e não como processo de aprendizagem dos alunos. Quanto ao conceito de letramento, as professoras o associam ao uso social da leitura e da escrita, mostrando que se apropriaram teoricamente desse conceito, mas demonstrando fragilidades no que dizem desenvolver no contexto de suas práticas quanto a alfabetizar e letrar simultaneamente.

Diante dos dados, chegamos ao entendimento de que a formação continuada promovida pelo PNAIC funcionou como uma oportunidade de encontro entre os professores para que pudessem compartilhar suas vivências e experiências a partir do que lhes era orientado e, ao mesmo tempo, promoveu a interação do alfabetizador com novas metodologias de ensino da leitura e da escrita. Os estudos que realizaram sobre os conceitos de alfabetização e de letramento lhes possibilitaram uma revisão sobre o que já sabiam sobre eles, aprofundando teoricamente, possibilitando-lhes novos entendimentos, mas, mesmo assim, ficaram alguns pressupostos que constituem esses conceitos em fase de aprendizagem, ou seja, na Zona de Desenvolvimento Proximal, o que implica que precisam de novas oportunidades formativas para que interajam com novos esclarecimentos sobre esses termos.

\section{REFERÊNCIAS}

AGUIAR, Wanda Maria J.; OZELLA, Sergio. Apreensão dos sentidos: aprimorando a proposta dos núcleos de significação. Revista Brasileira de Estudos Pedagógicos. Brasília, v. 94, n. 236, p. 299-322, jan./abr. 2013. Disponível em: http://www.scielo.br/pdf/rbeped/v94n236/15.pdf Acesso em: 23 de abril de 2019. 
ALBUQUERQUE, Eliana Borges Correia de. Conceituando alfabetização e letramento. In: SANTOS, Carmi Ferraz; MENDONÇA, Márcia (orgs). Alfabetização e Letramento: conceitos e relações. 1 ed. $1^{a}$ reimp. Belo Horizonte: Autêntica, 2007. 152 p. p. 11-21. Disponível em: http://www.serdigital.com.br/ gerenciador/clientes/ceel/arquivos/22.pdf Acesso em: 29 de abril de 2020.

AURELIANO, Francisca Edilma Braga Soares. Política de Formação de Professores Alfabetizadores: especificidades e indagações acerca do Próletramento. In: TEMÓTEO, Antonia Sueli da Silva Gomes; SILVA, Silvânia Lúcia de Araújo (orgs). Estágio e Docência em Pedagogia: entrelaces de um mesmo fio condutor. Olinda, PE: Livro Rápido, 2012. p. 100-120.

BRASIL. Ministério da Educação. Pacto Nacional pela Alfabetização na Idade Certa. Caderno de Apresentação. Brasília: MEC/SEB, 2015a. Disponível em: http://pacto.mec.gov.br/images/pdf/Cadernos_2015/cadernos_novembro/ pnaic_cad_apresentacao.pdf. Acesso em: 21 de fevereiro de 2020.

BRASIL. Ministério da Educação. Pacto Nacional pela Alfabetização na Idade Certa. A oralidade, a leitura e a escrita no ciclo de alfabetização. Caderno 05. Brasília: MEC/SEB, 2015b. Disponível em: http://pacto.mec.gov.br/images/ pdf/Cadernos_2015/cadernos_novembro/pnaic_cad_5_19112015.pdf. Acesso em: 30 de fevereiro de 2020.

BRASIL. Ministério da Educação. Pacto Nacional pela Alfabetização na Idade Certa. Currículo na Alfabetização: concepções e princípios. Brasilia: MEC/ SEB, 2012a, Unidade 01, Ano 01. Cadernos do Pacto Nacional pela Alfabetização na Idade Certa. Disponível em: http:/ /www.pomerode.sc.gov.br/arquivos/SED/ ano1/unidade_01_ano_01(07_11_2012).pdf Acesso em: 26 de março de 2020.

BRASIL. Ministério da Educação. Portaria no 867, de 4 de julho de 2012. Institui o Pacto Nacional pela Alfabetização na Idade Certa e as ações do Pacto e define suas diretrizes gerais. In: Diário Oficial da União, Seção 1, No 129, quinta-feira, 5 de julho de 2012b. Disponível em: http://download.inep.gov.br/educacao_ basica/provinha_brasil/legislacao/2013/portaria_n867_4julho2012_provinha_ brasil.pdf Acesso em: 08 de março de 2020. 
BRASIL. Ministério da Educação. Portaria no 826 de 07 de julho de 2017. Dispõe sobre o Pacto Nacional pela Alfabetização na Idade Certa - PNAIC, suas ações, diretrizes gerais e a ação de formação no âmbito do Programa Novo Mais Educação - PNME. Diário Oficial da União, Seção 1, No 130, segunda-feira, 10 de julho de 2017. Disponível em: http://pesquisa.in.gov.br/imprensa/jsp/ visualiza $/$ index.jsp?jornal $=1 \&$ pagina $=20 \& d a t a=10 / 07 / 2017$. Acesso em: $10 \mathrm{de}$ junho de 2020.

BRASIL. Presidência da República. Lei $\mathrm{n}^{\circ} \mathbf{1 0 . 1 7 2}$ de 9 de janeiro de 2001. Aprova o Plano Nacional de Educação e dá outras providências. Disponível em: http://portal.mec.gov.br/arquivos/pdf/L10172.pdf Acesso em: 10 de junho de 2020.

BRASIL. Presidência da República. Decreto no 6.094, de 24 de abril de 2007. Dispõe sobre a implementação do Plano de Metas Compromisso Todos pela Educação... Disponível em: http://www.planalto.gov.br/ccivil_03/_Ato20072010/2007/Decreto/D6094.htm Acesso em: 10 de junho de 2020.

BRASIL. Presidência da República. Plano Nacional de Educação 2014-2024. Lei no 13.005, de 25 de junho de 2014, que aprova o Plano Nacional de Educação (PNE) e dá outras providências. Brasília, Câmara dos Deputados, Edições Câmara, 2014. 86 p. Disponível em: http://www.observatoriodopne.org.br/uploads/ reference/file/439/documento-referencia.pdf. Acesso em: 19 de março de 2020.

BRASIL. Presidência da República. Decreto $\mathbf{n}^{\mathbf{0}} \mathbf{9 . 7 6 5}$, de 11 de abril de 2019. Institui a Política Nacional de Alfabetização. Casa Civil: Subchefia para Assuntos Jurídicos: Brasília-DF. Disponível em: http://www.planalto.gov.br/ccivil_03/_ ato2019-2022/2019/decreto/D9765.htm. Acesso em: 28 de abril de 2020.

CABRAL NETO, Antônio; MELO SILVA, Claudia Luciene; SILVA, Lamara Fabia Lucena. Teoria do capital humano, educação, desenvolvimento econômico e suas implicações na formação de professores. Revista Principia. João Pessoa, n. 32, p. 35-41, 2016. Disponível em: http://periodicos.ifpb.edu.br/index.php/ principia/article/viewFile/1070/575. Acesso em: 21 de fevereiro de 2020.

CANÁRIO, Rui. A prática profissional na formação de professores. Inafop. Formação profissional de professores no ensino superior. Universidade de Aveiro, 2000. 
CANDAU, V. M. F. A formação continuada de professores: tendências atuais. In: REALI, Aline de M. R.; MIZUKAMI, M. da G. N. (Orgs). Formação de professores: tendências atuais. São Carlos: EDUFSCar, 1996. p. 139-152.

FREIRE, Paulo. A importância do ato de ler: em três artigos que se completam. São Paulo: Autores Associados: Cortez, 1989. (Coleção polêmicas do nosso tempo).

GATTI, Bernadete A.; BARRETO, Elba Siqueira de Sá. (Coord.). Professores do Brasil: impasses e desafios. Brasília: Unesco, 2009.

LUKÁCS, G. Prolegômenos para uma ontologia do ser social: questões de princípios para uma. ontologia hoje tornada possível. São Paulo: Boitempo, 2010.

MORAIS, Artur. G. Apropriação do sistema de notação alfabética e o desenvolvimento de habilidades de reflexão fonológica. Letras de Hoje. Porto Alegre, v. 39, n. 3, 2004. p. 35-48. Disponível em: http:/ / revistaseletronicas. pucrs.br/ojs/index.php/fale/article/view/13913 Acesso em: 27 de abril de 2020.

MORTATTI, Maria do Rosário Longo. Letramento, alfabetização, escolarização e educação. In. MORTATTI, Maria do Rosário Longo. Educação e Letramento. São Paulo: Editora UNESP. Col. Paradidáticos, 2004, p. 97-116.

SMOLKA, A. B. O (im)próprio e o (im)pertinente na apropriação das práticas sociais. In: Cadernos Cedes, ano XX, n 50, Abril/2000. p. 26-40.

SOARES, Magda. Letramento: um tema em três gêneros. 2. ed. $11^{a}$ reimpr. Belo Horizonte: Autêntica, 2006.

VYGOTSKY, L. S. A formação social da mente. São Paulo: Martins Fontes, 2007.

VYGOTSKY, L. S. A Construção do Pensamento e da Linguagem. São Paulo: Martins Fontes, 2009.

SOARES, Magda. Letramento e alfabetização: as muitas facetas. Revista Brasileira de Educação. Rio de Janeiro, Jan - Abr, n. 25, 2004. Disponível em: https://www.scielo.br/pdf/rbedu/n25/n25a01.pdf. Acesso em: 20 de março de 2020. 


\section{Francisca Edilma Braga Soares Aureliano}

Doutora e Mestre em Educação pela Universidade Federal do Rio Grande do Norte. Docente Orientadora do Programa Residência Pedagógica no Curso de Pedagogia da UERN. E-mail: edilmaaureliano@hotmail.com

\section{Luiz Carlos da Costa Silva Júnior}

Licenciado em Pedagogia pela Universidade do Estado do Rio Grande do Norte (UERN). Membro do Grupo de Pesquisa "Formação, Currículo e Ensino" (FORMACE) da UERN. Pesquisador do Projeto "Aproximações e distanciamentos da formação continuada do PNAIC do trabalho pedagógico do professor alfabetizador" desenvolvido entre 2017 e 2019 na Linha de Pesquisa: Formação de professores, estágio e práxis educativa do FORMACE. E-mail: luizcarloscostasilvajunior@outlook.com

Recebido em 27/04/2020

Aprovado em 28/06/2020 